\title{
Preparation and Characterization of Self-Emulsified Docetaxel
}

\author{
Gyeong Hae Kim, Ju Young Lee, Yun Mi Kang, Kkot Nim Kang, E. Sle Kim, Da Yeon Kim, \\ Jae Ho Kim, and Moon Suk Kim
}

Department of Molecular Science and Technology, Ajou University, Suwon 443-749, Republic of Korea

Correspondence should be addressed to Moon Suk Kim, moonskim@ajou.ac.kr

Received 3 June 2010; Revised 2 August 2010; Accepted 11 August 2010

Academic Editor: Lu Sun

Copyright (C 2011 Gyeong Hae Kim et al. This is an open access article distributed under the Creative Commons Attribution License, which permits unrestricted use, distribution, and reproduction in any medium, provided the original work is properly cited.

The aim of this paper was to prepare a self-microemulsifying docetaxel (Dtx) using PLGA, Tetraglycol, Labrasol, and Cremophor ELP. The prepared Dtx-loaded self-microemulsifying system (SMES) showed the initial size of the range of 80-100 nm with narrow size distribution and the negative zeta-potential values. Its morphology was a spherical shape by atomic force microscopy. In experiment of stability, Dtx-loaded SMES prepared in DW and BSA condition showed good stability at $37^{\circ} \mathrm{C}$ for 7 days. The viability of the B16F10 cells incubated with Dtx-loaded SMES, Dtx-solution, and Taxol were decreased as a function of incubation time. In conclusion, we confirmed that Dtx-loaded SMES showed an inhibitory effect for proliferation of B16F10 melanoma cells.

\section{Introduction}

The first-line treatment of various cancers includes surgery, radiotherapy, or a combined treatment regimen [1-4]. As second-line treatment for cancer, the chemotherapy using anticancer drugs may be treated to remove completely cancers [1-6]. Many highly potent anticancer drugs are clinically treated as available commercial products. However, the utility of these cancer chemotherapeutic drugs in clinical applications is limited by very low solubility in aqueous $[7,8]$.

Paclitaxel (Ptx), isolated from the bark of Taxus brevifolia, has significant activity against a variety of tumors such as breast cancer, advanced ovarian carcinoma, lung cancer, and head and neck carcinoma [9]. Docetaxel (Dtx) is also an anticancer drug belonging to the second generation of the taxoid family [10]. Ptx and Dtx are hydrophobic drugs with poor aqueous solubility $[11,12]$. To enhance solubility of Ptx, it is currently formulated for clinical application as Taxol by Cremophor EL-based solvent system containing dehydrated ethanol [13].

Recently, various formulations such as liposomes, emulsions, micelles, microspheres, and polymeric nanoparticles have been employed for the encapsulating Ptx and Dtx including several anticancer drugs [14-20]. The selection of a proper Ptx and Dtx encapsulating formulation is important to improve the instability problems such as subsequent precipitation of the solubilised hydrophobic Ptx and Dtx for in vivo treatment.

The poor water solubility of Ptx and Dtx can be improved by the formulation with oil, low molecular weight surfactants, and so forth. The self-microemulsifying system (SMES) are isotropic mixtures of oil, a surfactant, and cosurfactants, which form fine oil-in-water emulsions when exposed to aqueous media [21-23]. Thus, the SMES was found to be highly suitable for the incorporation of hydrophobic Ptx and Dtx. Because SMES may be a promising way to load hydrophobic Dtx in delivery system, here, we report on the preparation of Dtx-loaded SMES which could result in an improvement of stability of the solubilised hydrophobic Dtx in aqueous media.

\section{Materials and Methods}

2.1. Materials. Poly (d,l-lactide-co-glycolide) (PLGA, molecular weight, 8,000, 20,000 and 90,000 g/mole) was purchased from Boerhinger Ingelheim (Ingelheim, Germany). Docetaxel was purchased from Naprod Life Science Pvt, Ltd (India). Paclitaxel (Genexol) was purchased from Samyang 
TABLE 1: Formulation for the preparation of Dtx-loaded SMES.

\begin{tabular}{lccc}
\hline $\begin{array}{l}\text { Composition } \\
(\mathrm{g}, \mathrm{w} / \mathrm{w})\end{array}$ & $\mathrm{F} 1$ & $\begin{array}{c}\text { Formulation } \\
\text { F2 }\end{array}$ & $\mathrm{F} 3$ \\
\hline $\begin{array}{l}\text { Drug } \\
\text { (Docetaxel) }\end{array}$ & 0.003 & \\
\hline $\begin{array}{l}\text { Solubilizer } \\
\text { (Tetraglycol) }\end{array}$ & 0.5 & \\
\hline $\begin{array}{l}\text { PLGA 8k g/mol } \\
\text { PLGA 20k g/mol }\end{array}$ & 0.005 & 0.005 & \\
$\begin{array}{l}\text { PLGA 90k g/mol } \\
\text { Cosurfactant }\end{array}$ & 0.14 & \\
(Labrasol) & & 0.005 \\
\hline $\begin{array}{l}\text { Surfactant } \\
\text { (Cremophor ELP) }\end{array}$ & & 0.16 & \\
\hline \begin{tabular}{l} 
Zeta-potential $(\mathrm{mV})$ \\
\hline
\end{tabular} & $-7.7 \pm 0.4$ & $-2.8 \pm 1.3$ & $-4.3 \pm 0.6$ \\
\hline
\end{tabular}

Genex Co. (Seoul, Korea). Caprylocaproyl macrogol-8 glyceride (Labrasol) was obtained from Gattefosse (Westwood, NJ, USA). Cremophor ELP was purchased from BASF (Germany). Tetraglycol was purchased from Sigma Chemical Co. (St. Louis, MO, USA). All other chemicals were of reagent grade. The deionized water (DW) was prepared by a Milli-Q purification system from Millipore (Molsheim, France).

2.2. Preparation of Dtx-Loaded SMES, Dtx-Solution, and Taxol. A series of SMES was prepared in each of the various formulas with PLGA, docetaxel, solubilizer, surfactant, and cosurfactant. Briefly, PLGA, Dtx, Tetraglycol, Labrasol, and Cremophor ELP in the various ratios (Table 1) were added into the vial, followed by heating on a hot plate to $60-70^{\circ} \mathrm{C}$ with stirring and vortex mixing until Dtx had perfectly dissolved. A solution of $3 \mathrm{mg}$ of SMES was carefully weighed in $10 \mathrm{~mL}$ tube. It was then emulsified by contacting to $7 \mathrm{~mL} \mathrm{DW}$ and vortexed, followed by keeping at room temperature for about 30 minutes to use in subsequent studies. The prepared Dtx-loaded SMES used without any purification. A $6 \mathrm{mg}$ of Dtx and Ptx was added into $10 \mathrm{~mL}$ mixture of Cremophor EL and ethanol $(\mathrm{v} / \mathrm{v}=1 / 1)$ to prepare Dtx-solution and Taxol, respectively [19-21].

2.3. Dtx Encapsulation Efficiency. The Dtx-loaded SMES and Dtx-solution prepared as final concentration of $0.43 \mathrm{mg} / \mathrm{mL}$ of Dtx in $7 \mathrm{mLDW}$. The flask was allowed to equilibrate for 30 minutes at RT. The solution was thereafter filtered through a filter paper. The Dtx encapsulation efficiency in the solution was analyzed using a high-performance liquid chromatography (HPLC), Agilent 1200 series LC system equipped with detection at $220 \mathrm{~nm}$ using a diode array detector (Agilent Technologies, Inc., Santa Clara, USA). A Sunfire C18 column $(4.6 \times 150 \mathrm{~mm}, 5 \mu \mathrm{m})$ was used. The mobile phase consisted of a distilled water: acetonitrile: methanol $(41: 48: 11 \mathrm{v} / \mathrm{v})$ mixture, and the column was eluted at a flow rate of $1.0 \mathrm{~mL} / \mathrm{min}$. The Dtx encapsulation efficiency was calculated by comparison with the standard calibration curves prepared with known concentrations of Dtx. Three independent Dtx-loaded SMES experiments were performed for each Dtx encapsulation efficiency and then averaged.

2.4. Size Analysis of Dtx-Loaded SMES, Dtx-Solution and Taxol. For analysis, formulation $(50 \mu \mathrm{L})$ of Dtx-loaded SMES, Dtx-solution and Taxol were diluted with $50 \mathrm{~mL} \mathrm{DW}$ in volumetric flask, followed by vortex mixing gently mixed. The particle size, size distribution, and surface charge of resultant formulation were determined by dynamic light scattering (DLS, ELS-8000, Photal, Japan) at room temperature. The analysis was individually measured for three samples of Dtx-loaded SMES, Dtx-solution, and Taxol, and then calculated as average value using three individual sizes.

2.5. Morphology of Dtx-Loaded SMES. The shape and surface morphology were investigated by atomic force microscopy (AFM). A $10 \mu \mathrm{L}$ of Dtx-loaded SMES was transferred onto silicon wafer which was washed with $\mathrm{MeOH}$. The wafer was quickly placed in liquid nitrogen, followed by the freezedrying for 2 days. AFM measurements were carried out in the tapping mode with a nanoscope IV instrument (Digital Instruments Inc.).

2.6. Stability of Dtx-Loaded SMES, Dtx-Solution, and Taxol. Dtx-loaded SMES, Dtx-solution, and Taxol were prepared with $7 \mathrm{~mL}$ DW or a solution of $0.9 \% \mathrm{NaCl}$ and $5 \%$ bovine serum albumin (Bovogen, Australia) and individually placed in $10 \mathrm{~mL}$ tube. The tube was constantly shaken at $100 \mathrm{rpm}$ and $37^{\circ} \mathrm{C}$ for 7 days. At the set time, the droplet size was individually measured for three samples of Dtx-loaded SMES, Dtx-solution, and Taxol, and then calculated as average value.

2.7. Cell Culture. B16F10 melanoma cell line was obtained by Korea Cell Line Bank and cultured in culture media (MEM (Minimum Essential Medium, Gibco BRL, USA) supplemented with $10 \%$ fetal bovine serum (Gibco BRL, USA) and $1 \%$ PS (Penicillin streptomycin, Gibco BRL, USA)), and maintained at $37^{\circ} \mathrm{C}$ in $5 \% \mathrm{CO}_{2}$ humidified atmosphere. The cells were seeded into $75-\mathrm{cm}^{2}$ flasks, cultured, and changed medium every 2 days.

2.8. Cell Cytotoxicity Tests. B16F10 cell suspension $(2 \times$ $10^{4}$ cells/well) was seeded in a 48 -well plate. The cells were incubated overnight to allow for cell attachment under culture media. The cells were incubated without and with Dtxloaded SMES, Dtx-solution, and Taxol for 7 days without changing of culture media [19-21]. The final concentration of the Dtx and Ptx in the cell culture medium was adjusted to $1 \mu \mathrm{g} / \mathrm{mL}$. Cell viability was determined by using watersoluble enzyme substrate MTT which was converted to purple water-insoluble product formazan accumulated in the cytoplasm of viable cells. Cell viability of each well performed individually and then calculated as average value. In brief, $100 \mu \mathrm{L}$ of PBS solution of the MTT tetrazolium substrate ( $5 \mathrm{mg} / \mathrm{mL}$ ) was added after 1,4 , and 7 days. After incubation for $4 \mathrm{~h}$ at $37^{\circ} \mathrm{C}$, the resulting purple formazan precipitate was solubilized by the addition of $1 \mathrm{~mL}$ of DMSO and shaken 


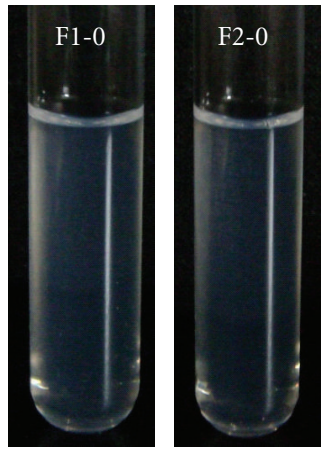

(a) 0 day in DW
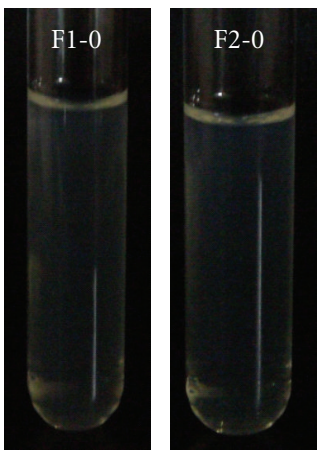

(c) 0 day in BSA
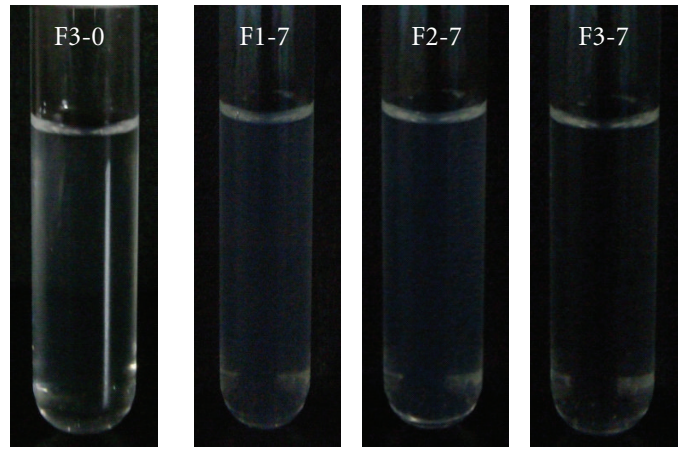

(b) 7 day in DW
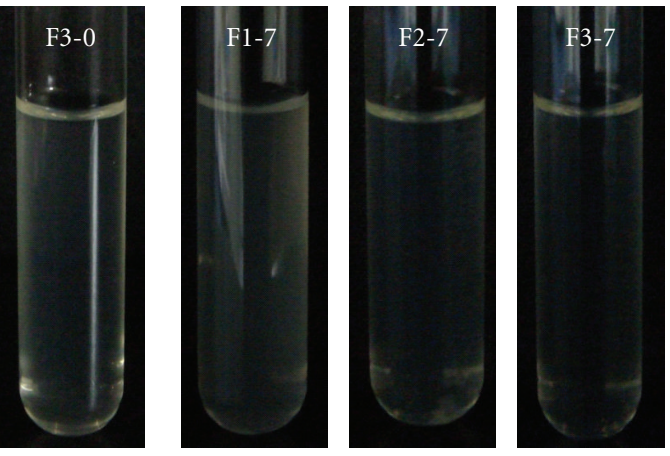

(d) 7 day in BSA

Figure 1: Pictures $(a, c)$ before and $(b, d)$ after incubation at $37^{\circ} \mathrm{C}$ for 7 days of Dtx-loaded SMES prepared in (a, b) DW and (c, d) BSA with different formulations F1-F3.

for 30 minutes. An aliquot from each well $(100 \mu \mathrm{L})$ was transferred to 96-well plates and then read using a plate reader of an ELISA (E-max, Molecular Device, USA). The optical density of each well was determined at $590 \mathrm{~nm}$.

2.9. Statistical Analysis. Cytotoxicity data were obtained from independent experiments in which each of the five treatment conditions were tested in triplicate. All data are presented as means \pm standard deviations (SD). The results were analyzed by one-way ANOVAs using the Prism 3.0 software package (GraphPad Software Inc., San Diego, CA, USA).

\section{Results and Discussion}

3.1. Preparation of Dtx-Loaded SMES. The Dtx-loaded SMES were prepared by using Dtx, tetraglycol, Cremophor ELP, Labrasol, and PLGA; the formulation is summarized in Table 1. The prepared Dtx-loaded SMES were observed visually. As shown in Figure 1(a) Dtx-loaded SMES (F1-F3) showed the transparent emulsion solution for all formulations, indicating that Dtx was successfully incorporated into the SMES. The Dtx encapsulation efficiency is above $70 \%$. Dtx-solution and Taxol showed the transparent solution.

The size and size distribution of Dtx-loaded SMES measured by DLS were shown in Table 2. The average size

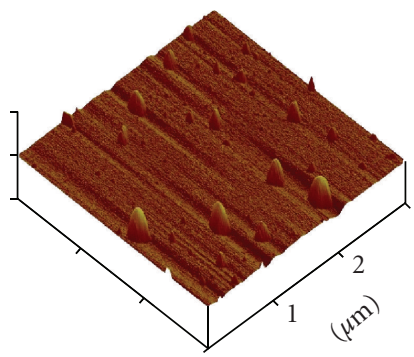

dtx-90k.002

$x 1 \mu \mathrm{m} / \mathrm{div}$

$z 50 \mathrm{~nm} / \mathrm{div}$

(a)

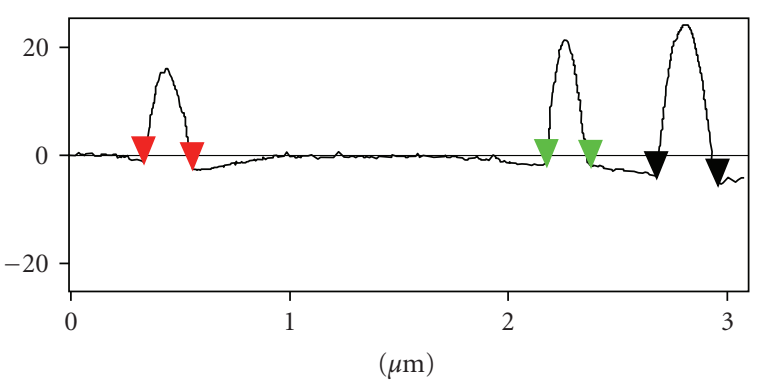

(c) 


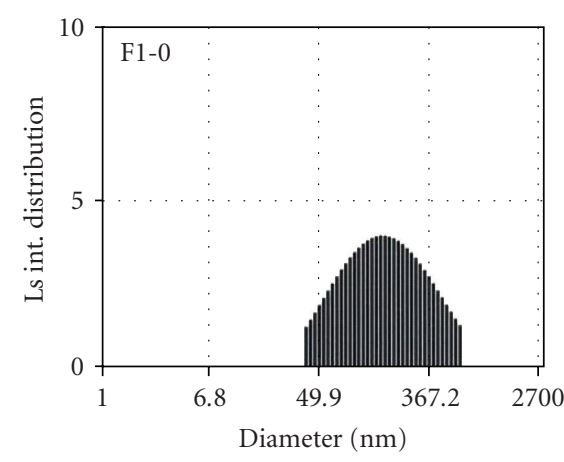

(a)

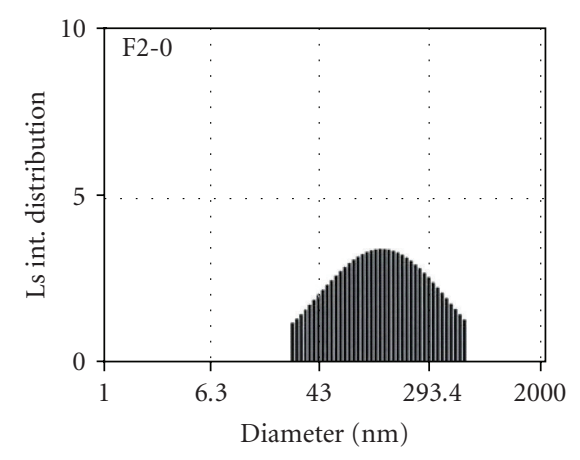

(d)

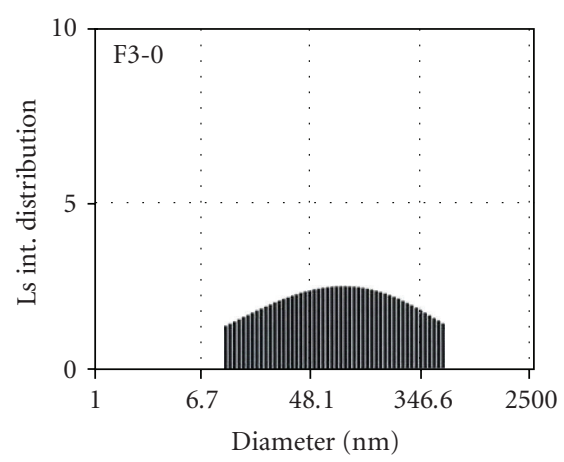

(g)

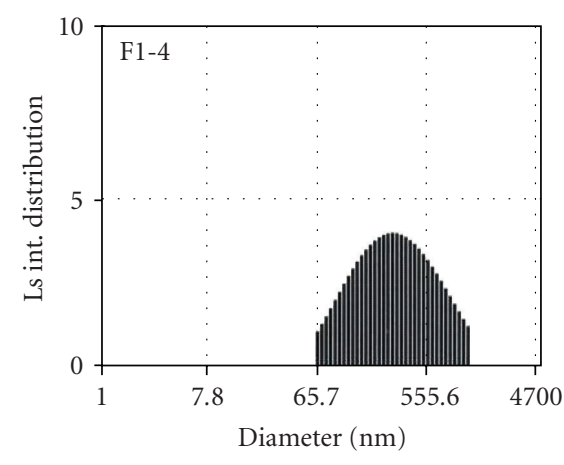

(b)

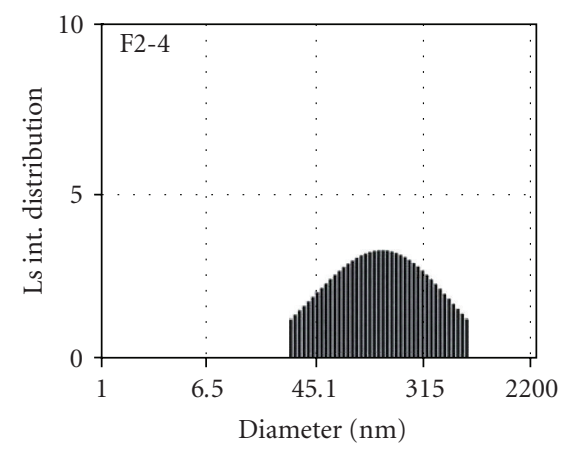

(e)

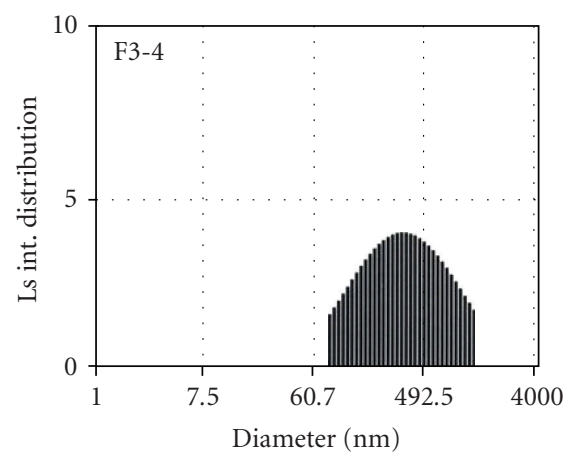

(h)

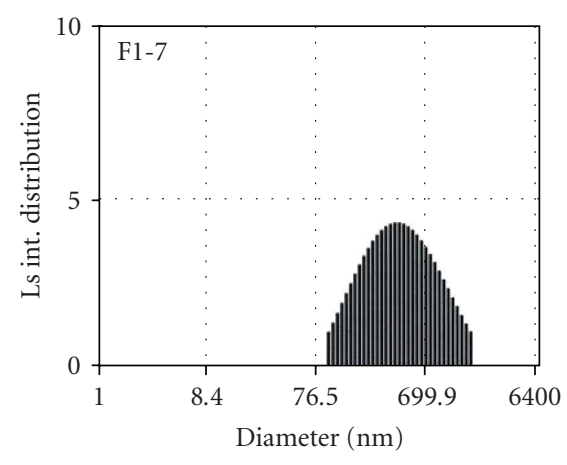

(c)

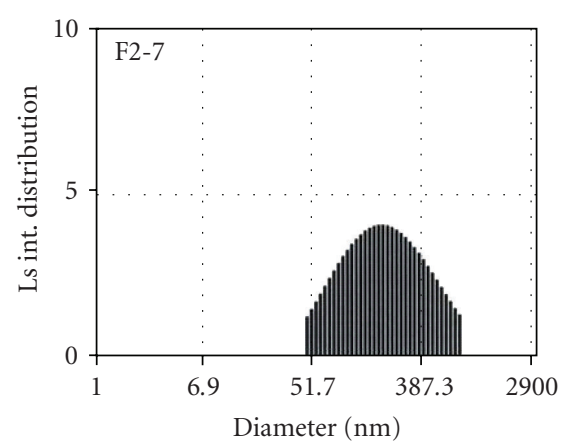

(f)

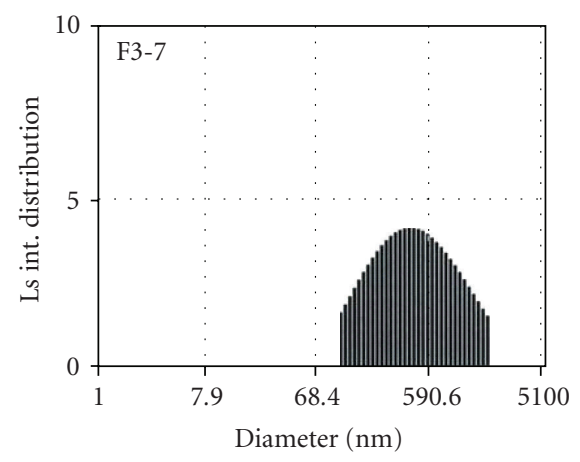

(i)

FIGURE 3: DLS images measured after incubation at $37^{\circ} \mathrm{C}$ at 0,4 , and 7 days of Dtx-loaded SMES prepared in BSA with different formulations F1-F3 (0, 4 and 7 represent the incubation time).

of the Dtx-loaded SMES determined from the DLS was in the range of $80-100 \mathrm{~nm}$. It seemed that the changes of PLGA molecular weight did not significantly affect the size of the resultant Dtx-loaded SMES. Even though the droplet size distribution was slightly broader for increasing PLGA molecular weight, F1-F3 is formulation with appropriate size. Meanwhile, Dtx-solution and Taxol showed the average size in the range of $200-300 \mathrm{~nm}$.

The AFM morphology of Dtx-loaded SMES showed the spherical shape with smooth surface as shown in Figure 2. A comparatively uniform droplet size of Dtx-loaded SMES was also observed at AFM, indicating no aggregation or adhesion among SMES.
3.2. Stability of Dtx-Loaded SMES. The stability of Dtxloaded SMES is important to maintain the in vivo therapeutic concentration of Dtx. Surface charge may be an important indication for the stability of Dtx-loaded SMES in medium. The zeta potential of the Dtx-loaded SMES indicates the negative surface charges (Table 1). This implies that the repulsion among the Dtx-loaded SMES with the same type of surface charge can provide stability.

To examine stability of the solubilised Dtx in DW and BSA condition, Dtx-loaded SMES, Dtx-solution, and Taxol were prepared with DW or a solution of $0.9 \% \mathrm{NaCl}$ and $5 \%$ BSA (Figures 1 and 4). The prepared Dtx-loaded SMES, Dtxsolution, and Taxol were constantly shaken at $100 \mathrm{rpm}$ and 
TABLE 2: The changes of average particle size by incubation for $0-7$ days at $37^{\circ} \mathrm{C}$ of Dtx-loaded SMES prepared in DW and BSA condition with different formulations F1-F3.

\begin{tabular}{|c|c|c|c|c|c|c|c|}
\hline \multirow{2}{*}{\multicolumn{2}{|c|}{$\begin{array}{l}\text { Condition } \\
\text { Formulation }\end{array}$}} & \multicolumn{3}{|c|}{ In DW } & \multicolumn{3}{|c|}{ In BSA condition ${ }^{\mathrm{a}}$} \\
\hline & & F1 & $\mathrm{F} 2$ & F3 & $\mathrm{F} 1$ & $\mathrm{~F} 2$ & F3 \\
\hline \multirow{3}{*}{ Particle size $(\mathrm{nm})^{\mathrm{b}}$} & Initial & $85 \pm 1$ & $92 \pm 3$ & $93 \pm 13$ & $116 \pm 4$ & $87 \pm 2$ & $113 \pm 8$ \\
\hline & 4 days & $93 \pm 5$ & $88 \pm 4$ & $77 \pm 20$ & $218 \pm 15$ & $93 \pm 6$ & $167 \pm 11$ \\
\hline & 7 days & $115 \pm 5$ & $99 \pm 4$ & $93 \pm 15$ & $234 \pm 3$ & $126 \pm 9$ & $226 \pm 3$ \\
\hline
\end{tabular}

${ }^{\mathrm{a}} \mathrm{A}$ solution of $0.9 \% \mathrm{NaCl}$ and $5 \%$ bovine serum albumin.

${ }^{\mathrm{b}}$ The mean and standard deviation of particle size for each formulation was calculated by individual measurement of three formulations.

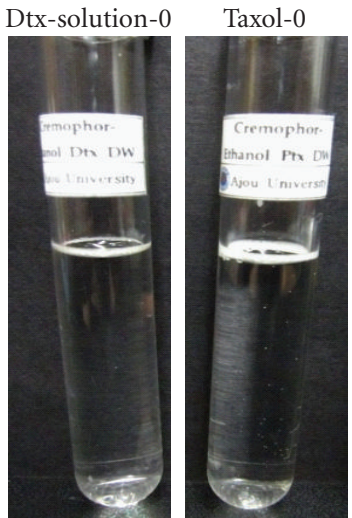

(a) 0 day in DW

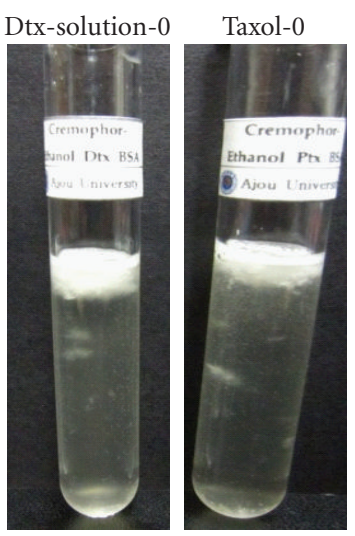

(c) 0 day in BSA

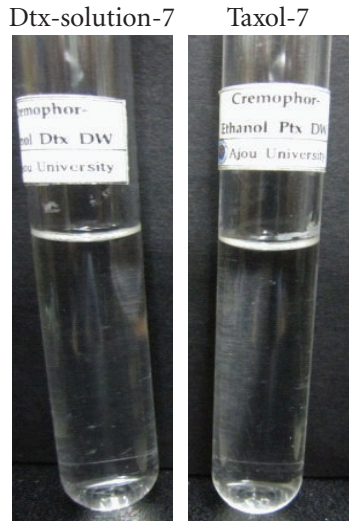

(b) 7 day in DW

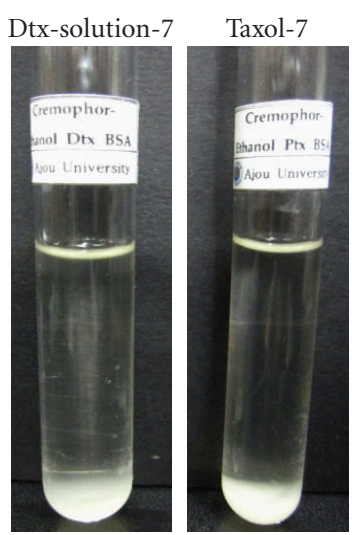

(d) 7 day in BSA
Figure 4: Pictures (a, c) before and (b, d) after incubation at $37^{\circ} \mathrm{C}$ for 7 days of Dtx-solution and Taxol prepared in (a,b) DW and (c, d) BSA.

$37^{\circ} \mathrm{C}$ for 7 days. There is a little change of particle size for F1-F3, Dtx-solution, and Taxol prepared in DW as shown in Figures 1(b) and 1(d), indicating the stability of Dtx-loaded SMES, Dtx-solution, and Taxol in DW.

For Dtx-loaded SMES, Dtx-solution, and Taxol prepared in BSA, the size of Dtx-loaded SMES steadily increased as a function of time (Table 2). The sizes of F1 and F3 at 7 days were approximately two times larger than those at 0 day. Meanwhile, F2 was maintained the original size for at least 4 days and only increased from 87 to $126 \mathrm{~nm}$ (Figure 3 ). It can be noted that proper Dtx encapsulating formulation can lead to stability of solubilised Dtx. Meanwhile Dtx-solution and

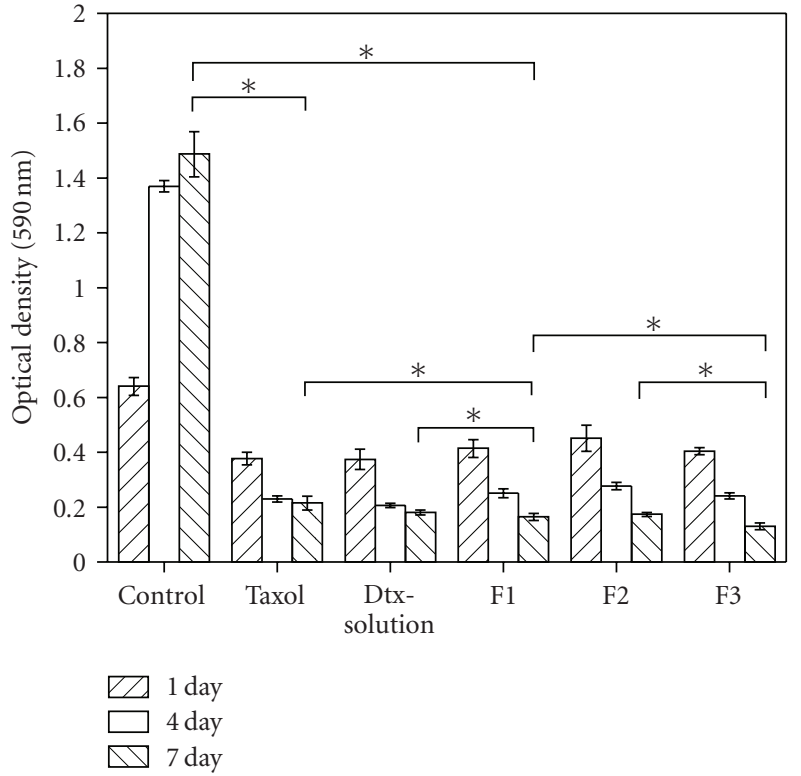

FIGURE 5: In vitro cytotoxicity of B16F10 melanoma cell against Dtx-loaded SMES of formulations F1, F2, and F3 for 1, 4, and 7 days. The cells grown on a culture plate without Dtx-loaded SMES were used as the control and the cells with Taxol and Dtx-solution were used for comparison $\left({ }^{*} P<.001\right)$.

Taxol precipitated immediately in BSA condition, indicating nonstability of Dtx-solution and Taxol (Figure 4).

3.3. Antitumor Activity of Dtx-Loaded SMES. The cytotoxicity for Dtx-loaded SMES (F1-F3), Dtx-solution, and Taxol for comparison was evaluated using B16F10 melanoma cell line (Figure 5). The B16F10 cells in the control experiment proliferated as a function of culture time. However, the viability of the B16F10 cells incubated with Dtx-loaded SMES (F1-F3) was approximately $50 \%-60 \%$ and $30 \%-$ $40 \%$ at 4 days and 7 days, indicating that increasing the incubation time from 24 to $48 \mathrm{~h}$ led to more cell death. A similar viability of the B16F10 cells was observed when Dtx-solution and Taxol were used for 4 days. However, the viability of the B16F10 cells for Dtx-solution and Taxol was maintained when the incubation time was extended to 7 days. This indicates that the Dtx-loaded SMES was somewhat more effective in inhibition of B16F10 cell proliferation than Dtx-solution and Taxol. Thus, it appeared that the slightly 
improved inhibition of B16F10 cell proliferation may be due to the Dtx-loaded SMES's stability.

\section{Conclusion}

The authors prepared the Dtx-loaded SMES to improve their stability. The prepared Dtx-loaded SMES showed a spherical shape in the range of $80-90 \mathrm{~nm}$. The authors found that the formulation of the Dtx-loaded SMES prepared in DW and BSA showed a little change in the particle size for 7 days. Dtx-loaded SMES showed an inhibitory effect on B16F10 melanoma proliferation. Thus, further research on the animal model using Dtx-loaded SMES prepared in this work is now in progress.

\section{Acknowledgments}

This paper was supported by a grant from the new faculty research fund of Ajou University, KMOHW (Grant no. A050082) and Priority Research Centers Program through NRF funded by the Ministry of Education, Science and Technology (2009-0093826).

\section{References}

[1] L. M. Gommersall, M. Arya, I. Mushtaq, and P. Duffy, "Current challenges in Wilms' tumor management," Nature Clinical Practice Oncology, vol. 2, no. 6, pp. 298-304, 2005.

[2] M. Reni, E. Mazza, A. Tosoni, and A. A. Brandes, "Novel therapeutics in adult malignant brain gliomas," Expert Opinion on Investigational Drugs, vol. 14, no. 6, pp. 643-657, 2005.

[3] C. E. Saadeh, "Chemotherapy- and radiotherapy-induced oral mucositis: review of preventive strategies and treatment," Pharmacotherapy, vol. 25, no. 4, pp. 540-554, 2005.

[4] R. Garcia-Carbonero and J. G. Supko, "Current perspectives on the clinical experience, pharmacology, and continued development of the camptothecins," Clinical Cancer Research, vol. 8, no. 3, pp. 641-661, 2002.

[5] A. Margaritis and B. Manocha, "Controlled release of doxorubicin from doxorubicin/ $\gamma$-polyglutamic acid ionic complex," Journal of Nanomaterials, vol. 2010, Article ID 780171, 9 pages, 2010.

[6] S. U. Choi and S. Y. Han, "Targeting cancer stem cells," Tissue Engineering and Regenerative Medicine, vol. 6, pp. 100-103, 2009.

[7] K. Cho, X. Wang, S. Nie, Z. Chen, and D. M. Shin, "Therapeutic nanoparticles for drug delivery in cancer," Clinical Cancer Research, vol. 14, no. 5, pp. 1310-1316, 2008.

[8] P. Li and L. Zhao, "Developing early formulations: practice and perspective," International Journal of Pharmaceutics, vol. 341, no. 1-2, pp. 1-19, 2007.

[9] J. P. Jain, M. Sokolsky, N. Kumar, and A. J. Domb, "Fatty acid based biodegradable polymer," Polymer Reviews, vol. 48, no. 1, pp. 156-191, 2008.

[10] Z. Xu, L. Chen, W. Gu et al., "The performance of docetaxelloaded solid lipid nanoparticles targeted to hepatocellular carcinoma," Biomaterials, vol. 30, no. 2, pp. 226-232, 2009.

[11] J. Y. Lee, K. S. Kim, Y. M. Kang et al., "In vivo efficacy of paclitaxel-loaded injectable in situ-forming gel against subcutaneous tumor growth," International Journal of Pharmaceutics, vol. 392, no. 1-2, pp. 51-56, 2010.
[12] A. Sparreboom, O. van Tellingen, W. J. Nooijen, and J. H. Beijnen, "Preclinical pharmacokinetics of paclitaxel and docetaxel," Anti-Cancer Drugs, vol. 9, no. 1, pp. 1-17, 1998.

[13] R. M. Straubinger, A. Sharma, M. Murray, and E. Mayhew, "Novel Taxol formulations: Taxol-containing liposomes," Journal of the National Cancer Institute. Monographs, no. 15, pp. 69-78, 1993.

[14] J. H. Park, S. Lee, J.-H. Kim, K. Park, K. Kim, and I. C. Kwon, "Polymeric nanomedicine for cancer therapy," Progress in Polymer Science, vol. 33, no. 1, pp. 113-137, 2008.

[15] S.-S. Feng, L. Mei, P. Anitha, C. W. Gan, and W. Zhou, "Poly(lactide)-vitamin E derivative/montmorillonite nanoparticle formulations for the oral delivery of Docetaxel," Biomaterials, vol. 30, no. 19, pp. 3297-3306, 2009.

[16] N. T. Huynh, C. Passirani, P. Saulnier, and J. P. Benoit, "Lipid nanocapsules: a new platform for nanomedicine," International Journal of Pharmaceutics, vol. 379, no. 2, pp. 201209, 2009.

[17] J. Portilla-Arias, R. Patil, J. Hu et al., "Nanoconjugate platforms development based in $\operatorname{poly}(\beta, \mathrm{L}-$ malic acid) methyl esters for tumor drug delivery," Journal of Nanomaterials, vol. 2010, Article ID 825363, 8 pages, 2010.

[18] T. Hekmatara, S. Gelperina, V. Vogel, S.-R. Yang, and J. Kreuter, "Encapsulation of water-insoluble drugs in poly(butyl cyanoacrylate) nanoparticles," Journal of Nanoscience and Nanotechnology, vol. 9, no. 8, pp. 5091-5098, 2009.

[19] W. Qiao, B. Wang, Y. Wang, L. Yang, Y. Zhang, and P. Shao, "Cancer therapy based on nanomaterials and nanocarrier systems," Journal of Nanomaterials, vol. 2010, Article ID 796303, 9 pages, 2010.

[20] R. Tong and J. Cheng, "Anticancer polymeric nanomedicines," Polymer Reviews, vol. 47, no. 3, pp. 345-381, 2007.

[21] P. Gao, B. D. Rush, W. P. Pfund et al., "Development of a supersaturable SEDDS (S-SEDDS) formulation of paclitaxel with improved oral bioavailability," Journal of Pharmaceutical Sciences, vol. 92, no. 12, pp. 2386-2398, 2003.

[22] S. Y. Lee, H. Hyun, J. Y. Youn et al., "Preparation of nanoemulsified paclitaxel using MPEG-PLGA diblock copolymers," Colloids and Surfaces A, vol. 313-314, pp. 126-130, 2008.

[23] Y. Liu, P. Zhang, N. Feng, X. Zhang, S. Wu, and J. Zhao, "Optimization and in situ intestinal absorption of selfmicroemulsifying drug delivery system of oridonin," International Journal of Pharmaceutics, vol. 365, no. 1-2, pp. 136-142, 2009. 

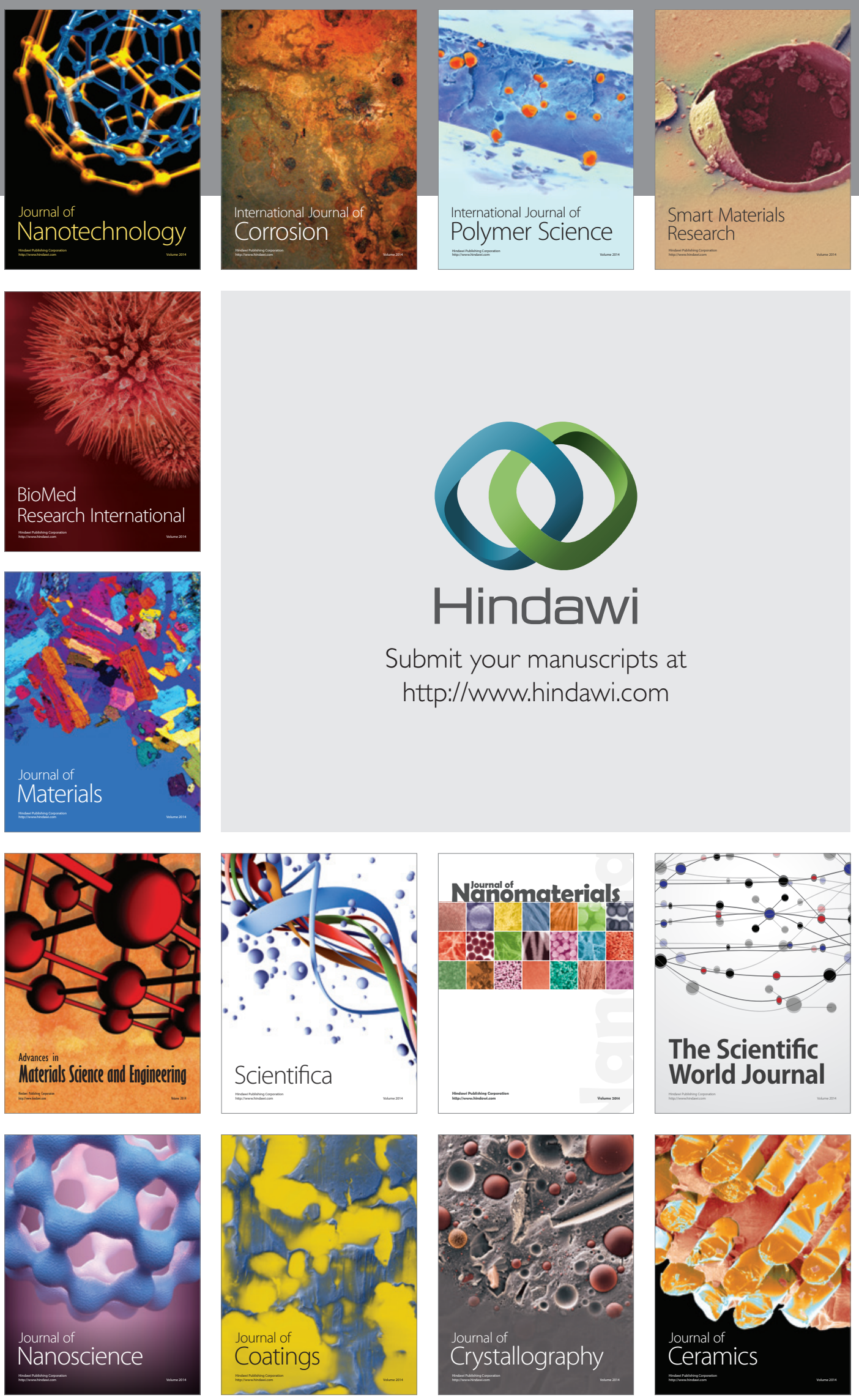

The Scientific World Journal

Submit your manuscripts at

http://www.hindawi.com

\section{World Journal}

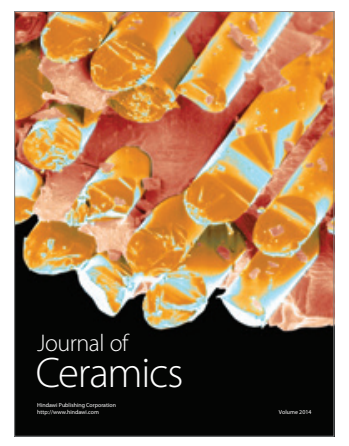

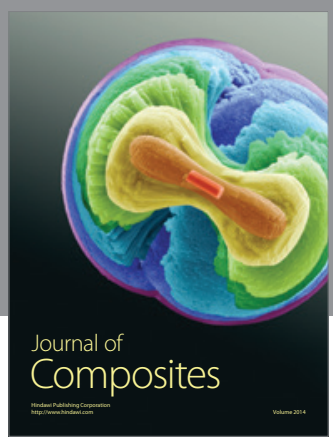
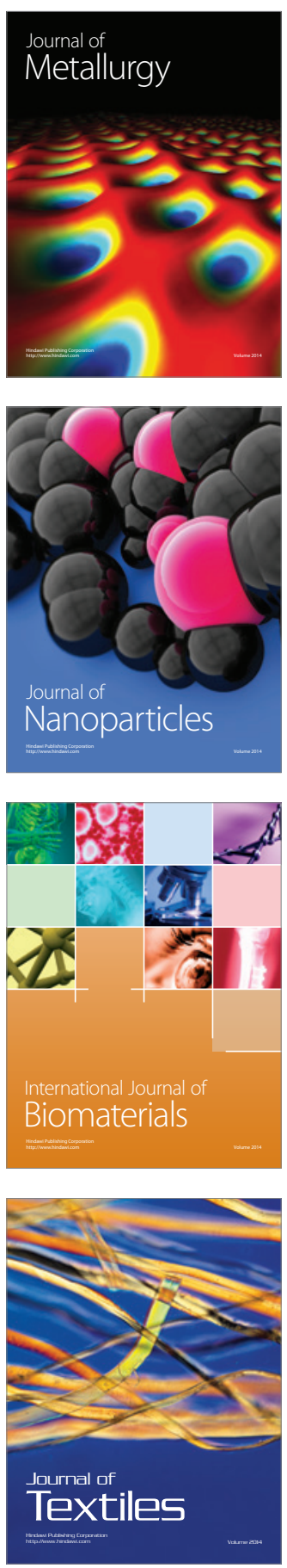